\title{
Ziprasidone versus Olanzapine in the weight gain associated with the treatment of schizophrenia: A six-month double-blind randomized parallel group study
}

\author{
Enric Alvarez* \\ Miguel Bernardo** \\ José Ramón Gutiérrez Casares ${ }^{\star \star \star}$ \\ Ángel L. Montejo ${ }^{\star \star \star \star}$ \\ * Department of Psychiatry. Hospital de \\ la Santa Creu i Sant Pau. CIBERSAM, \\ Universitat Autónoma de Barcelona, \\ IBSantpau Barcelona \\ ** Department of Psychiatry, Hospital Clinic \\ de Barcelona, CIBERSAM, University of \\ Barcelona, IDIBAPS, Barcelona \\ *** Complejo Hospitalario Universitario \\ de Badajoz. Servicio Extremeño de \\ Salud, Badajoz

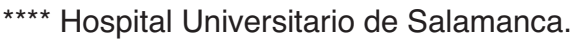 \\ School of Medicine, University of \\ Salamanca, Salamanca \\ SPAIN
}

\begin{abstract}
Background and Objectives: Previous data from safety analysis indicate that olanzapine can result in substantial weight gain, while no change has been observed with ziprasidone. Obesity may be a threat to health and cause subjects to discontinue their antipsychotic medication. To further evaluate the differential effects of ziprasidone and olanzapine on weight gain, a study was carried out having body weight as the primary efficacy endpoint.

Methods: A six-month randomized, double-blind, parallel study was carried out in male and female subjects aged 18-70 years with a primary diagnosis of schizophrenia (DSM-IV-TR) and a clinical condition requiring treatment initiation with a new antipsychotic, ziprasidone or olanzapine 1:1, to assess treatment-related weight changes. Fifty patients were included. Efficacy outcomes were assessed at baseline and at weeks 1, 4, 12, 18 and 24. The primary efficacy endpoint was the percent change from baseline in body weight at week 24. Safety was also assessed.

Results: At week 24, there was a significantly greater increase in body weight $(7.5 \%$, $\mathrm{p}<0.0001)$ in patients treated with olanzapine than in those treated with ziprasidone and
\end{abstract}


the number of subjects who had a weight gain $\geq 7 \%$ was significantly higher in the olanzapine compared to the ziprasidone group $(\mathrm{n}=11[47.8 \%])$ vs $\mathrm{n}=3[11.1 \%]$; OR $=6.246$, $\mathrm{p}$-value $=0.0150)$. PANNS-N significantly decreased in both groups. Most AEs were moderate or mild in both groups.

Conclusions: Olanzapine increases body weight significantly over ziprasidone at week 24. However, treatment with either ziprasidone or olanzapine improved PANSS positive, negative and general psychopathology scores and was well tolerated.

Received: 22 November 2011

Revised: 31 May 2012

Accepted: 4 June 2012

\section{Introduction}

Schizophrenic patients show a higher prevalence of obesity, glucose intolerance and type 2 diabetes mellitus, with a genetic link to enzymes involved in glycolysis ${ }^{1,2}$, and a higher rate of cardiovascular events ${ }^{3}$. Moreover, many second generation antipsychotics are associated with a higher risk for weight gain $^{2,4}$, insulin resistance, hyperglycemia and dyslipidemia $^{5}$. The combination of these different factors, genetic susceptibility, a sedentary lifestyle and poor diet and the adverse side effects of the antipsychotic treatment, represent an important risk factor for cardiovascular disease in patients treated with atypical antipsychotics ${ }^{6}$. Not only is obesity a threat to health and longevity, but it may also cause subjects to discontinue their antipsychotic medication ${ }^{7}$.

Both ziprasidone and olanzapine are efficient atypical antipsychotics frequently used in the treatment of schizophrenia and schizoid disorders. Atypical antipsychotic drugs show better efficacy and less adverse side effects than typical antipsychotics ${ }^{8,9}$. However, they are still prone to cause unwanted effects, including hypostatic hypotension ${ }^{10}$, somnolence $^{11}$, weight gain ${ }^{1,2}$, dyslipidemia ${ }^{12}$, hyperglycemia and diabetes mellitus ${ }^{5}$ and hyperprolactinaemia, which may generate fer- tility problems, sexual dysfunction and reduced bone mineral density ${ }^{13,14}$.

Previous studies have shown no changes in weight or metabolism in subjects treated with ziprasidone $^{1,2,15}$, Ziprasidone shows low propensity to cause extrapyramidal side effects (EPS) or laboratory abnormalities ${ }^{8,16,17}$, and does not negatively affect the sexual function of schizophrenic patients ${ }^{18}$. Ziprasidone has been reported to cause weight loss and reduction in serum lipid levels ${ }^{19,20}$.

Olanzapine is one of the most frequently prescribed antipsychotic drugs, with proven efficacy for schizophrenia symptoms ${ }^{21-23}$. However, olanzapine stands among the atypical antipsychotic drugs that induce weight gain $^{24,25}$, being also associated with substantial increases in total cholesterol, triglycerides, LDL and fasting insulin ${ }^{20,26,27}$. In previous studies comparing ziprasidone vs. olanzapine, exclusively or combined with other treatments, olanzapine showed significantly greater increases in weight and BMI and a higher probability of rapid weight gain than any other treatment ${ }^{7,20,26,27}$. However, all these studies had an efficacy variable as the primary variable, being weight assessment only part of the safety study.

Antipsychotic treatments are often longterm and it is necessary to consider the in- 
creased risk for metabolic alterations in patient care. Therefore, this randomized, double-blind study was designed to specifically address the issue of weight gain in the long-term (6 month), this being the primary variable. Also, considering that other factors are related to the patients disposition and compliance with treatment, this study assessed quality of life, general functioning, preferences and attitude to treatment, in order to provide more information on issues to be addressed in these longterm treatments and to discuss their relationship with the main purpose.

\section{Methods}

A six-month randomized, multi-center, parallel, double-blind study was carried out from April 2003 through February 2007 to estimate and compare the effects of ziprasidone versus olanzapine on body weight in the treatment of subjects with schizophrenia.

The study was conducted at 11 centers across Spain. Male or female subjects aged 18-70 years with a primary diagnosis of schizophrenia, according to the DSM-IV-TR ${ }^{28}$, and a clinical condition requiring treatment initiation with a new antipsychotic drug were enrolled. Patients, or their legal representative, gave their informed consent. Exclusion criteria: history of clinically significant physical illness or ECG abnormalities (e.g. QTc $>500$ $\mathrm{ms}$ ), clinically significant abnormal laboratory values, epilepsy, seizures, psychosurgery, lack of response or previous intolerance to olanzapine or ziprasidone; pregnancy or lactation; serological evidence of HIV or hepatitis; treatment with either drug within the 6 months previous to screening; patient unable or with difficulties to comply with the study protocol; immediate risk of committing harm to self or others; concurrent treatment with antipsychotic agents after randomization; depot antipsychotic medication within one month of entry; treatment with antidepressants or mood stabilizers within two weeks of randomization; substance abuse within previous 3 months; organic mental disease; treatment with a research clinical drugs within 30 days before randomization.

The study was developed in agreement with the declaration of Helsinki ${ }^{29}$ and the study protocol was approved by the Ethics Committees corresponding to the centers involved and by the Medicinal Products for Human Use Department of the Medicine and Health Products Spanish Agency (AEMPS).

Subjects were included in the study 12 hours after the previous antipsychotic dose, except for subjects treated with a depot antipsychotic (see above), and were randomly allocated in a 1:1 ratio.

\section{Treatment dosage and visit schedule}

Dosage was flexible within 3 levels: Low (ziprasidone 40mg BID or olanzapine $5 \mathrm{mg}$ BID), Medium (ziprasidone 60mg BID or olanzapine 15mg QD) and High (ziprasidone $80 \mathrm{mg}$ BID or olanzapine 10mg BID). Treatment was initiated at low dose for days 1-7 and from day 3 onwards, the dose could be adjusted.

The treatment phase (6 months) included 6 visits: Day 1 (Week 0), Week 1, Week 4, Week 12, Week 18 and Week 24. Follow-up visit (Week 48) performed six months after treatment completion. Study medication was reported from visit 1 through 6. Subjects who showed insufficient response at any time during the study, as indicated by a Clinical Global Impression of Improvement (CGI-I) score of $\geq 6$, were withdrawn. 


\section{Efficacy and safety assessments}

The efficacy outcomes measured were weight, BMI and waist circumference (WC); blood pressure and pulse; the positive and negative syndrome scale $(\mathrm{PANSS})^{30}$; the Clinical Global Impression (CGI) scale ${ }^{31}$ and another for improvement (CGI-I); patient's physical activity; the patient preference scale (PPS), to measure patient's satisfaction with medication; the Spanish version of the Health Utilities Index-Mark 3 (HUI-3) ${ }^{32,22}$. Appetite was measured by a visual analogue scale (VAS), a subjective quantification method. The patient marks his/her appetite level since the last visit on a horizontal line marked 0 (no appetite) left and 10 (extremely hungry) on the right. The distance from 0 is then measured in $\mathrm{cm}$ and appetite level quantified.

All efficacy outcomes were assessed at visit 1 (baseline values) and additionally: CGI-S, CGI-I and PANSS from visit 2 to 7, appetite and patient's physical activity from visit 3 to 6, PPS and HUI-3 at visits 4 and 6

Safety evaluations included clinical monitoring, electrocardiograms, vital signs, adverse events (AEs), and safety laboratory tests. Safety assessments were reported according to Worldwide Safety Standards (WSS) Version 3 requirements.

\section{Statistical analysis}

All analyses were performed on the intent-to-treat (ITT) population, using the SAS® version 8.2 or higher. Statistical tests were 2 tailed and p-values of 0.05 or smaller were considered statistically significant. Treatment was fitted as a categorical. 95\% confidence intervals (CI) were constructed around all estimated treatment differences. All changes were analyzed by analysis of covariance (ANCOVA) including effects for treatment group and baseline value (if applicable). Descriptive statistics were used to summarize all safety assessments. Adverse events were coded according to the Medical Dictionary for Regulatory Activities (MedDRA). No formal statistical testing was performed on safety parameters.

\section{Results}

\section{Subject disposition and drug dose}

Although the study was initially intended for 112 patients, in the study period only 58 subjects were screened. Finally, 50 ITT patients were included: 27 to ziprasidone and 23 to olanzapine. During the study period a total of 29 subjects discontinued their treatment (19 in the ziprasidone group and 10 in the olanzapine). Although most discontinuations were not related to the study drug, 2 (one in each group) were due to lack of efficacy and 7 (5 in the ziprasidone and 2 in the olanzapine) were due to drug-related adverse events. Median duration of treatment was lower for the ziprasidone (52.5 days [1-175 days]) than for the olanzapine group (164 days [2-181 days]; $32 \%$ of subjects in the ziprasidone group and $58 \%$ in the olanzapine completed the study.

During the treatment phase, patients on ziprasidone received a mean dose of $107.4 \pm$ $27.3 \mathrm{mg} /$ day and patients on olanzapine received a mean dose of $15 \pm 3.3 \mathrm{mg} /$ day.

\section{Baseline characteristics}

Demographic characteristics were homogeneous between both groups showing no significant differences. ITT patients were aged 19-63 years, being the majority in between 18-44 years. Detailed demographic 
data are provided in table 1 . Similar numbers of subjects in both treatment groups received concomitant drug treatments during the study (26 in the ziprasidone and 21 in the olanza- pine group). The most frequently taken (by $\geq$ 5 subjects in either treatment group) in both treatment groups were lorazepam, lormetazepam, and risperidone.

Table 1

Demographic and clinical characteristics of ITT population

\begin{tabular}{|c|c|c|c|}
\hline & \multirow{2}{*}{$\begin{array}{c}\text { ZIPRASIDONE } \\
\mathrm{N}=27 \\
\mathrm{n}(\%) \text { or mean } \pm \mathrm{SD}\end{array}$} & \multirow{2}{*}{$\begin{array}{c}\text { OLANZAPINE } \\
\mathrm{N}=23 \\
\mathrm{n}(\%) \text { or mean } \pm \mathrm{SD}\end{array}$} & \multirow[b]{2}{*}{ p-value } \\
\hline & & & \\
\hline Sex: Male & $20(74.1)$ & $15(65.2)$ & 0.4957 \\
\hline Age (years) & $40.8 \pm 9.2$ & $35.6 \pm 13.5$ & 0.1098 \\
\hline Race & & & 0.235 \\
\hline White & $25(92.6)$ & $22(95.7)$ & \\
\hline Black & $0(0)$ & $1(4.4)$ & \\
\hline Other & $2(7.4)$ & $0(0)$ & \\
\hline Weight (kg) & $81 \pm 18.7$ & $72.4 \pm 11.5$ & 0.0533 \\
\hline BMI $\left(\mathrm{kg} / \mathrm{m}^{2}\right)$ & $28 \pm 5.3$ & $25.3 \pm 4$ & 0.0555 \\
\hline Height (cm) & $170.4 \pm 11.3$ & $169.4 \pm 8.4$ & 0.7317 \\
\hline Concomitant dis. (at least 1 ) & $4(14.3)$ & $5(20.8)$ & \\
\hline Cardiac dis. & $1(3.6)$ & $0(0)$ & \\
\hline Endocrine (hypothyroidism) & $1(3.6)$ & $1(4.8)$ & \\
\hline GI dis. & $1(3.6)$ & $1(4.8)$ & \\
\hline General dis. & $0(0)$ & $1(4.8)$ & \\
\hline Immune (seasonal allergy) & $0(0)$ & $1(4.8)$ & \\
\hline Investigations & $1(3.6)$ & $0(0)$ & \\
\hline Metabolism & $2(7.1)$ & $0(0)$ & \\
\hline Vascular dis. & $2(7.1)$ & $3(12.5)$ & \\
\hline Past history (at least 1 dis.) & $11(39.3)$ & $8(33.3)$ & \\
\hline Cardiac dis. & $0(0)$ & $1(4.8)$ & \\
\hline Congenital (phimosis) & $1(3.6)$ & $0(0)$ & \\
\hline Endocrine (hyperthyroidism) & $1(3.6)$ & $0(0)$ & \\
\hline GI dis. & $4(14.3)$ & $2(8.3)$ & \\
\hline Hepatobiliary disease & $4(14.3)$ & $0(0)$ & \\
\hline Injury & $0(0)$ & $1(4.8)$ & \\
\hline Metabolism & $1(3.6)$ & $1(4.8)$ & \\
\hline Musculoskeletal dis. & $1(3.6)$ & $2(8.3)$ & \\
\hline Neoplasm & $1(3.6)$ & $2(8.3)$ & \\
\hline Reproductive system dis. & $1(3.6)$ & $0(0)$ & \\
\hline Respiratory (asthma) & $1(3.6)$ & $0(0)$ & \\
\hline Skin (dermal cyst) & $0(0)$ & $1(4.8)$ & \\
\hline Surgical and medical procedures & $3(10.7)$ & $4(16.7)$ & \\
\hline
\end{tabular}




\section{Effects on Weight Gain}

Body weight was stable at week 24 in the ziprasidone group, showing no significant difference with basal weight $(-0.1 \%$ percent decrease; n.s.) while there was a statistically significant increase from baseline in the olanzapine group $(7.4 \%$ percent increase in body weight from baseline, $\mathrm{p}<0.0001$ ) (Table 2). The difference between treatment groups in body weight change from baseline was sta- tistically significant at all time points and olanzapine-treated patients showed significant weight increase from baseline in all visits (Table 2). The number of subjects who had a weight gain $\geq 7 \%$ at week 24 was significantly lower in the ziprasidone $(\mathrm{n}=3$ [11.1\%]) than in the olanzapine group $(n=11$ $[47.8 \%])(\mathrm{OR}=6.246 ; \mathrm{p}=0.0150)$. The difference between treatment groups was also evident at weeks $12(\mathrm{p}=0.0266)$ and $18(\mathrm{p}=$ 0.0261) (data not shown).

Table 2

Percent change in body weight from baseline

\begin{tabular}{|c|c|c|c|c|c|c|c|c|}
\hline \multirow[b]{2}{*}{ Visits } & \multicolumn{2}{|c|}{ Ziprasidone $(\mathrm{N}=27)$} & \multicolumn{2}{|c|}{ Olanzapine $(\mathrm{N}=23)$} & \multicolumn{4}{|c|}{ Ziprasidone-Olanzapine } \\
\hline & LSM & $\mathrm{p}$-value & LSM & $\mathrm{p}$-value & Diff. & Lo.L & Up.L & $\mathrm{p}$-value \\
\hline Week 1 & -0.1 & 0.6344 & 1 & 0.0029 & -1.2 & -2.1 & -0.2 & 0.0138 \\
\hline Week 4 & 0 & 0.9491 & 3.3 & $<0.0001$ & -3.3 & -5.2 & -1.4 & 0.0009 \\
\hline Week 12 & -0.4 & 0.6571 & 5.4 & $<0.0001$ & -5.8 & -8.4 & -3.2 & $<0.0001$ \\
\hline Week 18 & -0.2 & 0.8641 & 7.1 & $<0.0001$ & -7.3 & -10.3 & -4.2 & $<0.0001$ \\
\hline Week 24 & -0.1 & 0.9076 & 7.4 & $<0.0001$ & -7.6 & -10.8 & -4.3 & $<0.0001$ \\
\hline
\end{tabular}

LSM: least squares means; Diff.: difference between ziprasidone and olanzapine least squares means; Lo.L: C.I. 95\% lower limit; Up.L: C.I. $95 \%$ upper limit. Significance p<0.05.

The secondary endpoints at week 24 are summarized in Table 3. Ziprasidone treated patients did not experience any significant change in WC and BMI at 24 weeks, while olanzapine treated patients suffered a significant increase in both parameters, resulting in a significant difference in the 24-week LSM (least square means) of either value between groups.

\section{Efficacy Results}

Ziprasidone treatment resulted in a significant decrease (i. e. improvement) of PANNS$\mathrm{N}$ and olanzapine in a significant decrease of all PANNS subscales. All decreases were significantly larger in the olanzapine than in the ziprasidone group. However, there was no significant difference in the number of patients that experienced improvement of schizophrenia symptoms between groups, as assessed by PANNS (7 [26.9\%]) ziprasidone vs. 11 [47.8\%] olanzapine; $\mathrm{p}=0.1385$ ). On the CGI-S scale, 19 patients in the ziprasidone group and 16 in the olanzapine were moderately to markedly ill at baseline; at 24 weeks, there were 19 and 12 patients, respectively (data not shown). On the CGI-I scale, 5 patients in the ziprasidone group and 4 in the olanzapine were "much improved" and 1 in the ziprasidone and 4 in the olanzapine "very much improved" at 24 weeks (data not shown). Subjects treated with olanzapine had better ratings for symptom exacerbation (CGI-S) (OR: 3.321, p = 0.0286) and improvement (CGI-I) (OR: 3.512, p = 0.0307) 
Table 3

Secondary endpoints at week 24

\begin{tabular}{|c|c|c|c|c|c|c|c|c|}
\hline \multirow[t]{2}{*}{ Parameter } & \multicolumn{3}{|c|}{ Ziprasidone } & \multicolumn{3}{|c|}{ Olanzapine } & \multicolumn{2}{|c|}{$\begin{array}{l}\text { Ziprasidone } \\
\text { Olanzapine }\end{array}$} \\
\hline & $\mathrm{N}$ & LSM & $\mathrm{p}$-value & $\mathrm{N}$ & LSM & p-value & Diff. & p-value \\
\hline BMI & 26 & 0 & 0.8713 & 23 & 1.8 & $<0.0001$ & -1.8 & 0.0001 \\
\hline WC & 27 & 0.3 & 0.8147 & 23 & 4.6 & 0.0013 & -4.3 & 0.0285 \\
\hline PANSS-P & 26 & -1.3 & 0.0920 & 23 & -4.1 & $<0.0001$ & 2.8 & 0.0187 \\
\hline PANSS-N & 26 & -1.9 & 0.0440 & 23 & -5.6 & $<0.0001$ & 3.7 & 0.0093 \\
\hline PANSS-GP & 26 & -2.3 & 0.1609 & 23 & -7.7 & $<0.0001$ & 5.4 & 0.0271 \\
\hline PANSS-C & 26 & 0.6 & 0.5025 & 23 & 1.5 & 0.0878 & -0.9 & 0.4367 \\
\hline PANSS Total & 26 & -5.4 & 0.0719 & 23 & -17.5 & $<0.0001$ & 12 & 0.0089 \\
\hline PANSS resp. & 26 & NA & NA & 23 & NA & NA & $0.401 *$ & 0.1385 \\
\hline CGI-S & 27 & NA & NA & 23 & NA & NA & $3.321 *$ & 0.0286 \\
\hline CGI-S resp. & 27 & NA & NA & 23 & NA & NA & $0.425^{*}$ & 0.2379 \\
\hline CGI-I & 24 & NA & NA & 19 & NA & NA & $3.512 *$ & 0.0307 \\
\hline CGI-I resp. & 24 & NA & NA & 19 & NA & NA & $0.487 *$ & 0.2823 \\
\hline PPS & 17 & -1.3 & $<0.0001$ & 20 & -0.3 & 0.3790 & -1.1 & 0.0161 \\
\hline Appetite (VAS) & 20 & -10.6 & 0.0018 & 21 & 0.2 & 0.9451 & -10.8 & 0.0280 \\
\hline Physical activity & 22 & NA & NA & 22 & NA & NA & $0.256^{*}$ & 0.0331 \\
\hline Standing SBP & 26 & 1.3 & 0.6368 & 23 & -3 & 0.2948 & 4.3 & 0.2740 \\
\hline Standing DBP & 26 & 4.5 & 0.0133 & 23 & 1.4 & 0.4565 & 3.1 & 0.2488 \\
\hline Standing HR & 25 & -8.2 & 0.0007 & 23 & -1.6 & 0.5222 & -6.6 & 0.0662 \\
\hline Sitting SBP & 26 & 4.3 & 0.0932 & 23 & 0.7 & 0.7951 & 3.6 & 0.3392 \\
\hline Sitting DBP & 26 & 2.3 & 0.2088 & 23 & 0 & 0.9986 & 2.3 & 0.3919 \\
\hline Sitting HR & 25 & -5.6 & 0.0635 & 23 & -5.6 & 0.0753 & 0 & 0.9991 \\
\hline
\end{tabular}

* Odds-ratio has been calculated for the endpoint; LSM: least squares means; BMI: Body Mass Index; WC: Waist Circumference; PANSS: Positive and Negative Syndrome Scale; CGI: Clinical Global Impression; resp.: responders; NA: Not Available; PPS: Patient Preference Scale; VAS: Visual Analogue Scale; SBP: Systolic Blood Pressure; DBP: Diastolic Blood Pressure; HR: Heart Rate. Shadowed numbers: significant p-values $(\mathrm{p}<0.05)$.

at week 24 than those treated with ziprasidone. However, and similarly to PANNS results, there were no significant differences in the number of patients that showed improvement in CGI-S (4 [14.8\%] on ziprasidone vs. 7 [30.4\%] on olanzapine; $p=0.2379$ ) and CGI-I (6 [25.0\%] on ziprasidone vs. 8 [42.1\%] on olanzapine; $p=0.2823$ ) between groups. Better satisfaction with medication, as measured in PPS, was observed in the ziprasi- done group than in the olanzapine group $(\mathrm{p}=$ 0.0161). As shown in Table 4, appetite also decreased significantly in ziprasidone-treated patients, while it increased slightly in the olanzapine group. Although appetite increase in the latter did not reach statistical significance, the change was statistically different between treatment groups. There were no significant differences between treatment groups' blood pressure and heart rate. 
Table 4

Changes in appetite from Baseline (measured by Visual Analogue Scale)

\begin{tabular}{|c|c|c|c|c|c|c|c|c|}
\hline \multirow[b]{2}{*}{ Visits } & \multicolumn{2}{|c|}{$\begin{array}{l}\text { Ziprasidone } \\
(\mathrm{N}=20)\end{array}$} & \multicolumn{2}{|c|}{$\begin{array}{c}\text { Olanzapine } \\
(\mathrm{N}=21)\end{array}$} & \multicolumn{4}{|c|}{ Ziprasidone-Olanzapine } \\
\hline & LSM & $\mathrm{p}$-value & LSM & $\mathrm{p}$-value & Diff. & Lo.L & Up.L & p-value \\
\hline Week 4 & -5.4 & 0.0563 & 3.4 & 0.2242 & -8.8 & -16.8 & -0.8 & 0.0328 \\
\hline Week 12 & -9.1 & 0.0096 & 0.3 & 0.9285 & -9.4 & -19.3 & 0.5 & 0.0627 \\
\hline Week 18 & -6.9 & 0.0287 & 2.4 & 0.4433 & -9.3 & -18.2 & -0.3 & 0.0423 \\
\hline Week 24 & -10.6 & 0.0018 & 0.2 & 0.9451 & -10.8 & -20.4 & -1.2 & 0.0280 \\
\hline
\end{tabular}

LSM: least squares means; Diff.: difference between ziprasidone and olanzapine least squares means; Lo.L: C.I. $95 \%$ lower limit; Up.L: C.I. $95 \%$ upper limit. Significance p $<0.05$. All changes analyzed by ANCOVA, including effects for treatment group and baseline value.

\section{Safety Results}

No deaths were reported during this study. Adverse effects during this study and laboratory tests have been summarized in Table 5 . Half the AE events in each group were treatment-related (ziprasidone: sedation, anxiety, restlessness, schizophrenia and hypersomnia; olanzapine: schizophrenia, restlessness). Twenty-one treatment-related AEs were experienced by 15 subjects $(53.6 \%)$ in the ziprasidone group and 11 by 8 subjects $(33.3 \%)$ in the olanzapine group.

\section{Discussion}

According to the study protocol, 78 patients (39 in each group) should have been evaluated for a statistical power of $80 \%$ to detect a difference of $5 \mathrm{~kg}$, estimating an $\mathrm{SD}=$ 7.7. However, the final ITT population included was 50 patients. Although this could have represented a limitation, the difference in body weight between groups at 24 weeks was $7.5 \%$ ( $\mathrm{SD}=4.5)$. Power was $99 \%$ and the result was better than initially planned.

In agreement with previous studies, body weight was stable in the ziprasidone group while there was a statistically significant increase from baseline in the olanzapine group at every time point ${ }^{6,7}$. Accordingly, ziprasidone-treated patients did not experience any significant change in WC and BMI, while olanzapine-treated patients suffered a significant increase in both parameters and weight. In a previous study ${ }^{34}$, the percentage of olanzapine-treated patients with $\geq 7 \%$ weight gain was even higher: $60 \%$ of patients at 3 months which rose to $80 \%$ after 1 year of olanzapine treatment. The olanzapine dosage of the mentioned study was similar or lower than that of our study. This fact is not surprising, since dose has not been related to olanzapine weight gain, but related to therapeutic response $^{25}$. Patients with maximal olanzapine benefit on symptoms are also those at a highest risk of significant weight gain.

Variations in food intake have been proposed as a possible cause for these effects on weight. In this study, appetite decreased significantly in ziprasidone treated patients while no significant change in olanzapine treated patients was reported. Appetite stimulation is strongly correlated with antipsychotic drug affinity for $\mathrm{H} 1$ and alpha1 adrenergic receptors ${ }^{35}$ and appetite decrease in ziprasidone treated patients is probably associated to the drug's low affinity for H1 re- 
Table 5

Safety Data

\begin{tabular}{lcc} 
& Ziprasidone & Olanzapine \\
\hline Adverse Effects & & 0 \\
Deaths & 2 & 3 \\
Number of Serious Adverse Effects (SAEs) & 1 & 0 \\
$\quad$ Anxiety & 1 & 2 \\
$\quad$ Schizophrenia & 0 & 1 \\
$\quad$ Epilepsy & 21 & 16 \\
Number of subjects reporting Adverse Effects (AEs) & 41 & 27 \\
Number of AEs reported & 16 & 9 \\
$\quad$ Psychiatric & 10 & 5 \\
$\quad$ Nervous System Disorders & 4 & 1 \\
$\quad$ General AEs & 2 & 2 \\
$\quad$ Gastrointestinal disorders & 9 & 10 \\
$\quad$ Other & 10 & 4 \\
Discontinuation due to AEs & & 22 \\
\hline Laboratory Tests & 22 & 10 \\
\hline Subjects suitable for Lab. Tests (Nr of patients) & 13 & 3 \\
Laboratory Abnormalities (Nr of patients) & 3 & 1 \\
$\quad$ Increased total neutrophils (Nr of patients) & 3 & 2 \\
Decreased absolute Lymphocytes (Nr of patients) & 5 & $\mathrm{mg} / \mathrm{dL}$ \\
$\quad$ Increased CRP (>1.25 x ULN) (Nr of patients) & $-16,1 \mathrm{ng} / \mathrm{mL}$ & $-22,1 \mathrm{~mL}$ \\
$\quad$ Prolactin decrease (median change from baseline) & $-4 \mathrm{mg} / \mathrm{dL}$ & \\
$\quad$ PLDL Cholesterol (median change from baseline) & & \\
\hline
\end{tabular}

ceptor. The olanzapine treated patients did not show a significant increase in appetite, but still showed a significant increase in body weight, suggesting that other mechanisms may be involved in olanzapine-induced weight gain. Tschoner et al. found higher fasting glucose and an increased score in an insulin resistance model in patients treated with olanzapine, while this effect could not be observed in ziprasidone treated patients, indicating the involvement of this effect in olanzapine-induced weight gain ${ }^{6}$. Animal studies have shown that olanzapine, but not ziprasidone, stimulates the consumption of fat $^{36}$ and that chronic treatment with olanzapine impairs lipolysis by adipocytes ${ }^{37}$. Also, previous studies have found cholesterol, triglycerides and LDL-cholesterol increase in olanzapine treated patients, and not in ziprasidone treated individuals ${ }^{6,38}$. Physical activity is significantly reduced in olanzapine treated patients ${ }^{39,40}$, but the OR of physical exercise in this study significantly favors olanzapine over ziprasidone treated patients and hence, does not explain the difference in weight gain.

Olanzapine-treated patients showed significantly better outcomes in PANNS subscales than those under ziprasidone treatment, confirming results of a previous study ${ }^{20}$. Participants in that study had discontinued a pre- 
vious treatment due to intolerance, making difficult the comparison with our present study. The dose of ziprasidone was similar but olanzapine dose was higher. Olanzapine shows increasing dose-response curves for schizophrenia symptoms ${ }^{21,41}$, which might explain the greater improvement in PANNS compared to ziprasidone in the study with higher olanzapine dose. However, olanzapine doses higher than $20 \mathrm{mg}$ /day have been described to present greater risks of important side effects ${ }^{42,43}$.

In contrast, two other studies found no difference in efficacy between treatments. The study carried out by Lieberman et al. ${ }^{7}$ showed no significant differences in PANNS total score change from baseline nor between olanzapine and ziprasidone. Likewise, the study by Simpson et al. showed no differences in PANNS score improvement between groups $^{26,27}$. These studies used similar flexible doses as the ones we used found the same efficacy with either olanzapine or ziprasidone treatment. A plausible explanation might be that although ziprasidone is indicated for the treatment of schizophrenia at a dose range of 40-160 mg/day, the optimal dose is closer to $120 \mathrm{mg} /$ day $^{44}$ and the mean dose of our study, slightly lower than the mean doses of the other two studies, might not have been optimal. Furthermore, the bioavailable dose might have been even lower. Although ziprasidone plasma level shows a significant positive correlation with receptor occupancy, the dose does not predict plasma level ${ }^{44}$, since food can interfere on ziprasidone absorption ${ }^{45}$, affects may depend on medication timing.

There were 1.6 times more treatment discontinuations in the ziprasidone than in the olanzapine group, showing a higher fold difference between both treatments than in other studies $^{7,20}$. Most AEs were mild or moderate in both groups and included adverse events usually observed with these drugs ${ }^{20,34}$. PPS scale indicates that patients preferred ziprasidone over olanzapine.

This study shows a significantly greater increase in body weight at week 24 in patients treated with olanzapine compared to those treated with ziprasidone. The progressive appetite reduction reported may have contributed to the slight decrease in body weight observed in ziprasidone-treated patients. On the other hand, patients on olanzapine indicated some increase in their appetite, but changes in this group were not significant and did not show the progressive increase in variation that ziprasidone patients reported. The visual analogue scale is a subjective method for measuring appetite, and although differences in appetite were significant and results seemed consisted during the study, slightly increased appetite or lack of exercise do not appear responsible for the weight gain experienced by olanzapine-treated patients, suggesting other mechanisms. Fat food preference and metabolic dysregulation may play a role in the underlying cause. Both ziprasidone and olanzapine groups were well tolerated and showed a decrease in PANSS scores at week 24. Although the decrease was significantly greater for all scores in the olanzapine group, the possibility of reduced ziprasidone bioavailability cannot be ruled out.

In those patients for whom weight gain during the treatment of schizophrenia may be a problem, treatment with ziprasidone should be tried, because of its good safety profile in this field.

\section{Acknowledgements}

This study was funded by Pfizer.

Medical writing support was provided by Medical Statistics Consulting and was funded by Pfizer. 


\section{References}

1. Allison DB, Fontaine KR, Heo M, Mentore JL, Cappelleri JC, Chandler LP, et al. The distribution of body mass index among individuals with and without schizophrenia. $\mathrm{J}$ Clin Psychiatry 1999; 60(4): 215-220.

2. Baptista T, De Mendoza S, Beaulieu S, Bermudez A, Martinez M. The metabolic syndrome during atypical antipsychotic drug treatment: mechanisms and management. Metab Syndr Relat Disord 2004; 2(4): 290-307.

3. Enger C, Weatherby L, Reynolds RF, Glasser DB, Walker AM. Serious cardiovascular events and mortality among patients with schizophrenia. J Nerv Ment Dis 2004; 192(1): 19-27.

4. Allison DB, Mentore JL, Heo M, Chandler LP, Cappelleri JC, Infante MC, et al. Antipsychotic-induced weight gain: a comprehensive research synthesis. Am J Psychiatry 1999; 156(11): 1686-1696.

5. Kane JM, Barrett EJ, Casey DE, Correll CU, Gelenberg AJ, Klein S, et al. Metabolic effects of treatment with atypical antipsychotics. J Clin Psychiatry 2004; 65(11): 14471455 .

6. Tschoner A, Engl J, Rettenbacher M, Edlinger M, Kaser S, Tatarczyk T, et al. Effects of six second generation antipsychotics on body weight and metabolism - risk assessment and results from a prospective study. Pharmacopsychiatry 2009; 42(1): 29-34.

7. Lieberman JA, Stroup TS, McEvoy JP, Swartz MS, Rosenheck RA, Perkins DO, et al. Effectiveness of antipsychotic drugs in patients with chronic schizophrenia. $\mathrm{N}$ Engl J Med 2005; 353(12): 1209-1223.

8. King DJ. Drug treatment of the negative symptoms of schizophrenia. Eur Neuropsychopharmacol 1998; 8(1): 33-42.

9. Weiden P, Aquila R, Standard J. Atypical antipsychotic drugs and long-term outcome in schizophrenia. J Clin Psychiatry 1996; 57(Suppl 11): 53-60.

10. Drici MD, Priori S. Cardiovascular risks of atypical antipsychotic drug treatment. Pharmacoepidemiol Drug Saf 2007; 16(8): 882-890.

11. Gao K, Ganocy SJ, Gajwani P, Muzina DJ, Kemp DE, Calabrese JR. A review of sensitivity and tolerability of antipsychotics in patients with bipolar disorder or schizophrenia: focus on somnolence. J Clin Psychiatry 2008; 69(2): 302-309.

12. Nasrallah HA. Atypical antipsychotic-induced metabolic side effects: insights from receptor-binding profiles. Mol Psychiatry 2008; 13(1): 27-35.
13. Baldwin D, Mayers A. Sexual side-effects of antidepressant and antipsychotic drugs. Adv Psychiatr Treat 2003; 9(3): 202-210.

14. Montejo AL. Prolactin awareness: an essential consideration for physical health in schizophrenia. Eur Neuropsychopharmacol 2008; 18(Suppl 2): S108-114.

15. Keck PE, Jr., McElroy SL, Arnold LM. Ziprasidone: a new atypical antipsychotic. Expert Opin Pharmacother 2001; 2(6): 1033-1042.

16. Kane JM, Khanna S, Rajadhyaksha S, Giller E. Efficacy and tolerability of ziprasidone in patients with treatment-resistant schizophrenia. Int Clin Psychopharmacol 2006; 21(1): 21-28.

17. Keck P, Jr., Buffenstein A, Ferguson J, Feighner J, Jaffe W, Harrigan EP, et al. Ziprasidone 40 and $120 \mathrm{mg}$ /day in the acute exacerbation of schizophrenia and schizoaffective disorder: a 4-week placebo-controlled trial. Psychopharmacology (Berl) 1998; 140(2): 173-184.

18. Montejo AL, Rico-Villademoros F. Changes in sexual function for outpatients with schizophrenia or other psychotic disorders treated with ziprasidone in clinical practice settings: a 3-month prospective, observational study. J Clin Psychopharmacol 2008; 28(5): 568-570.

19. Kingsbury SJ, Fayek M, Trufasiu D, Zada J, Simpson GM. The apparent effects of ziprasidone on plasma lipids and glucose. J Clin Psychiatry 2001; 62(5): 347-349.

20. Stroup TS, Lieberman JA, McEvoy JP, Swartz MS, Davis SM, Rosenheck RA, et al. Effectiveness of olanzapine, quetiapine, risperidone, and ziprasidone in patients with chronic schizophrenia following discontinuation of a previous atypical antipsychotic. Am J Psychiatry 2006; 163(4): 611-622.

21. Beasley CM, Jr., Tollefson G, Tran P, Satterlee W, Sanger T, Hamilton S. Olanzapine versus placebo and haloperidol: acute phase results of the North American double-blind olanzapine trial. Neuropsychopharmacology 1996; 14(2): 111-123.

22. Conley RR, Mahmoud R. A randomized double-blind study of risperidone and olanzapine in the treatment of schizophrenia or schizoaffective disorder. Am J Psychiatry 2001; 158(5): 765-774.

23. Gomez JC, Crawford AM. Superior efficacy of olanzapine over haloperidol: analysis of patients with schizophrenia from a multicenter international trial. J Clin Psychiatry 2001; 62(Suppl 2): 6-11.

24. Bobes J, Rejas J, Garcia-Garcia M, Rico-Villademoros F, Garcia-Portilla MP, Fernandez I, et al. Weight gain in patients with schizophrenia treated with risperidone, olanzapine, quetiapine or haloperidol: results of the EIRE study. Schizophr Res 2003; 62(1-2): 77-88. 
25. Kinon BJ, Kaiser CJ, Ahmed S, Rotelli MD, KollackWalker S. Association between early and rapid weight gain and change in weight over one year of olanzapine therapy in patients with schizophrenia and related disorders. J Clin Psychopharmacol 2005; 25(3): 255-258.

26. Simpson GM, Glick ID, Weiden PJ, Romano SJ, Siu CO. Randomized, controlled, double-blind multicenter comparison of the efficacy and tolerability of ziprasidone and olanzapine in acutely ill inpatients with schizophrenia or schizoaffective disorder. Am J Psychiatry 2004; 161(10): 1837-1847.

27. Simpson GM, Weiden P, Pigott T, Murray S, Siu CO, Romano SJ. Six-month, blinded, multicenter continuation study of ziprasidone versus olanzapine in schizophrenia. Am J Psychiatry 2005; 162(8): 1535-1538.

28. American Psychiatric Association., American Psychiatric Association. Task Force on DSM-IV. Diagnostic and statistical manual of mental disorders: DSM-IV-TR. 4th ed. Washington, DC: American Psychiatric Association; 2000.

29. WMA. World Medical Association Declaration of Helsinki: ethical principles for medical research involving human subjects. J Postgrad Med. 2002; 48(3): 206-208.

30. Kay SR, Fiszbein A, Opler LA. The positive and negative syndrome scale (PANSS) for schizophrenia. Schizophr Bull 1987; 13(2): 261-276.

31. Guy W, National Institute of Mental Health (U.S.). Psychopharmacology Research Branch., Early Clinical Drug Evaluation Program. ECDEU assessment manual for psychopharmacology. Rev. ed. Rockville, Md.: U. S. Dept. of Health, Education, and Welfare, Public Health Service, Alcohol, Drug Abuse, and Mental Health Administration, National Institute of Mental Health, Psychopharmacology Research Branch, Division of Extramural Research Programs; 1976.

32. Feeny D, Furlong W, Boyle M, Torrance GW. Multiattribute health status classification systems. Health Utilities Index. Pharmacoeconomics 1995; 7(6): 490-502.

33. Ruiz M, Rejas J, Soto J, Pardo A, Rebollo I. [Adaptation and validation of the Health Utilities Index Mark 3 into Spanish and correction norms for Spanish population]. Med Clin (Barc) 2003; 120(3): 89-96.

34. McEvoy JP, Lieberman JA, Perkins DO, Hamer RM, $\mathrm{Gu} \mathrm{H}$, Lazarus A, et al. Efficacy and tolerability of olanzapine, quetiapine, and risperidone in the treatment of early psychosis: a randomized, double-blind 52-week comparison. Am J Psychiatry 2007; 164(7): 1050-1060.

35. Baptista T, Zarate J, Joober R, Colasante C, Beaulieu $\mathrm{S}$, Paez X, et al. Drug induced weight gain, an impediment to successful pharmacotherapy: focus on antipsychotics. Curr Drug Targets 2004; 5(3): 279-299.
36. Hartfield AW, Moore NA, Clifton PG. Effects of atypical antipsychotic drugs on intralipid intake and cocaine-induced hyperactivity in rats. Neuropsychopharmacology 2006; 31(9): 1938-1945.

37. Minet-Ringuet J, Even PC, Valet P, Carpene C, Visentin V, Prevot D, et al. Alterations of lipid metabolism and gene expression in rat adipocytes during chronic olanzapine treatment. Mol Psychiatry 2007; 12(6): 562-571.

38. Rettenbacher MA, Ebenbichler C, Hofer A, Kemmler G, Baumgartner S, Edlinger M, et al. Early changes of plasma lipids during treatment with atypical antipsychotics. Int Clin Psychopharmacol 2006; 21(6): 369-372.

39. Fell MJ, Anjum N, Dickinson K, Marshall KM, Peltola LM, Vickers S, et al. The distinct effects of subchronic antipsychotic drug treatment on macronutrient selection, body weight, adiposity, and metabolism in female rats. Psychopharmacology (Berl) 2007; 194(2): 221-231.

40. Fleischhaker C, Heiser P, Hennighausen K, HerpertzDahlmann B, Holtkamp K, Mehler-Wex C, et al. Clinical drug monitoring in child and adolescent psychiatry: side effects of atypical neuroleptics. J Child Adolesc Psychopharmacol 2006; 16(3): 308-316.

41. Fanous A, Lindenmayer JP. Schizophrenia and schizoaffective disorder treated with high doses of olanzapine. J Clin Psychopharmacol 1999; 19(3): 275-276.

42. Farah A. Atypicality of atypical antipsychotics. Prim Care Companion J Clin Psychiatry 2005; 7(6): 268-274.

43. Reich J. Use of high-dose olanzapine in refractory psychosis. Am J Psychiatry 1999; 156(4): 661.

44. Mamo D, Kapur S, Shammi CM, Papatheodorou G, Mann S, Therrien F, et al. A PET study of dopamine D2 and serotonin 5-HT2 receptor occupancy in patients with schizophrenia treated with therapeutic doses of ziprasidone. Am J Psychiatry 2004; 161(5): 818-825.

45. Hamelin BA, Allard S, Laplante L, Miceli J, Wilner $\mathrm{KD}$, Tremblay J, et al. The effect of timing of a standard meal on the pharmacokinetics and pharmacodynamics of the novel atypical antipsychotic agent ziprasidone. Pharmacotherapy $1998 ; 18(1): 9-15$.

Author for correspondence:

Enric Alvarez

Department of Psychiatry

Hospital de la Sta. Creu and St. Pau, Barcelona, Spain

C/ Sant Antoni Maria Claret, 167

08025 Barcelona

Phone: (+34) 932919000

E-mail: ealvarezm@santpau.cat 